\title{
MFI and FAU-Type Zeolites as Trapping Materials for Light Hydrocarbons Emission Control at Low Partial Pressure and High Temperature
}

\author{
Fortunato Migliardini, ${ }^{1}$ Fabio Iucolano, ${ }^{2}$ Domenico Caputo, ${ }^{2}$ and Pasquale Corbo ${ }^{1}$ \\ ${ }^{1}$ Istituto Motori, Consiglio Nazionale delle Ricerche, Via Marconi 8, 80125 Napoli, Italy \\ ${ }^{2}$ Dipartimento di Ingegneria Chimica, dei Materiali e della Produzione Industriale, Università di Napoli "Federico II", \\ P.le V. Tecchio 80, 80125 Napoli, Italy \\ Correspondence should be addressed to Pasquale Corbo; p.corbo@im.cnr.it
}

Received 21 November 2014; Accepted 24 February 2015

Academic Editor: Jean-Luc Blin

Copyright @ 2015 Fortunato Migliardini et al. This is an open access article distributed under the Creative Commons Attribution License, which permits unrestricted use, distribution, and reproduction in any medium, provided the original work is properly cited.

\begin{abstract}
The adsorption of light hydrocarbons (C2-C5 olefins and paraffins, toluene) on HZSM-5, silicalite, and HY was studied for application in treatment of exhaust streams of the petrochemical industry and of vehicles under cold start conditions. At this aim the trapping capability was evaluated on hydrated zeolites by breakthrough curves at low hydrocarbon partial pressure $(0-1 \mathrm{kPa})$, in the temperature range $298-523 \mathrm{~K}$ and at space velocity of $30000 \mathrm{~h}^{-1}$. The basic adsorption properties of materials were also verified for three selected hydrocarbons (ethylene, isobutene, and toluene) by equilibrium isotherms on dehydrated zeolites at $298 \mathrm{~K}$. The role of physicochemical characteristics of adsorbent materials was discussed in relation with their trapping capability of different types of hydrocarbons.
\end{abstract}

\section{Introduction}

Adsorption techniques have been studied in the past several years as methods for separation or capture of hydrocarbons (HC) in applications that require the recovery of these compounds in high purity (petrochemical industry) [1-3]. Liquefied petroleum gas and bottom contents of refinery deethanizer or depropanizer columns are the common industrial source of light hydrocarbons such as methane, ethane, propane, n-butane, and i-butane, which can be recovered and used as a fuel or petrochemical feed stocks $[4,5]$. Light hydrocarbons are also the main components of natural gas and represent a significant proportion of most crude oil [6]. More recently adsorption-based processes have been also proposed for the abatement of organic pollutants at the exhaust of light-duty gasoline vehicles under cold start conditions. This last application is justified by the future legislative limits for passenger car emissions incoming all over the world, which will become more and more stringent and will require the development of new technological solutions, including more effective after-treatment devices [7]. It is known that the largest fraction (more than $80 \%$ ) of the total organic pollutants flows out from the tailpipe during the short time following the engine startup (200 seconds). During this period the air/fuel ratio is on the rich side that implies more $\mathrm{HC}$ emissions, while the temperature of the three-way catalyst (TWC) is lower than its light-off value (473-573 K), which requires some minutes to be reached. The worldwide diffusion of hybrid vehicles makes the problem of HC cold start emission more critical, due to the higher number of ignition times occurring in this type of vehicle with respect to the conventional ones.

The three basic technologies that have been developed for the control of the cold start $\mathrm{HC}$ emissions are the close-coupled catalyst, the electrically heated catalyst, and the HC traps. An extensive review of these solutions, with a description of the related patents, is reported in [8]. The combination of catalytic converters with HC traps has been proposed in several patents and appears as the most promising technology in terms of efficiency and cost [8-10]. 
TABLE 1: Zeolitic materials used for adsorption tests.

\begin{tabular}{|c|c|c|c|c|c|}
\hline Sample & Form & $\mathrm{Si} / \mathrm{Al}$ & Pore opening, $\AA$ & Surface area ${ }^{\mathrm{a}}, \mathrm{m}^{2} / \mathrm{g}$ & Pore volume ${ }^{\mathrm{b}}, \mathrm{cm}^{3} / \mathrm{g}$ \\
\hline \multirow{2}{*}{ HZSM-5 } & \multirow{2}{*}{ Powder } & \multirow{2}{*}{15} & $5.3 \times 5.6$ & \multirow{2}{*}{405} & \multirow{2}{*}{0.24} \\
\hline & & & $5.1 \times 5.5$ & & \\
\hline \multirow{2}{*}{ Silicalite } & \multirow{2}{*}{ Powder } & \multirow{2}{*}{$\infty$} & $5.3 \times 5.6$ & \multirow{2}{*}{400} & \multirow{2}{*}{0.24} \\
\hline & & & $5.1 \times 5.5$ & & \\
\hline $\mathrm{HY}$ & Powder & 15 & 7.4 & 730 & 0.51 \\
\hline
\end{tabular}

These traps are constituted by a bed of adsorbent material able to catch hydrocarbons until the working temperature of the catalytic converter is reached. When the temperature of the exhaust gas increases, trapped hydrocarbons are desorbed and oxidized in the TWC. Then the fundamental features required for a successful hydrocarbon trap to be used in automotive applications are the high selectivity towards light hydrocarbons at relatively low temperature range (from room temperature to about $470 \mathrm{~K}$ ) and the low sorbate concentration levels.

The most suitable materials for HC trapping are carbonbased materials, silicoaluminophosphates and zeolites [8]. Activated carbons are effective and not expensive; however, they would be oxidized in the presence of oxygen and at the high temperature occurring in exhaust gases of an internal combustion engine. Among inorganic commercial adsorbents with high surface area zeolites are the preferred materials for the present application. They are crystalline aluminosilicates which exist in both natural and synthetic form, characterized by different $\mathrm{Si} / \mathrm{Al}$ ratios and a porosity of molecular size (3-10 $\AA$ ), uniquely determined by the unit structure of the crystal. As a consequence they have a high internal surface area (generally higher than $400 \mathrm{~m}^{2} / \mathrm{g}$ ) available for adsorption due to channels that uniformly penetrate the entire volume of the solid [12]. These materials have been used for adsorption-based separations for several decades, finding applications in numerous fields [13-15]. Zeolites have been object of many studies related with $\mathrm{HC}$ trapping, since a particular zeolite can be selected as a function of the type of $\mathrm{HC}$ to be trapped and of the particular gaseous environment they have to be removed from. In particular experimental data regarding the $\mathrm{HC}$ adsorption capacity of different zeolites, such as ZSM-5, Y, beta, mordenite, ferrierite, and silicalite, are extensively reported in literature [16-21]. The properties of these materials have been evaluated with respect to main parameters that can affect the $\mathrm{HC}$ adsorption, that is, molecular size of $\mathrm{HC}$, zeolite pore size, and $\mathrm{Al}$ content, but all these data refer to selected hydrocarbons studied at room temperature. A comparison between the adsorption properties of different zeolites and silicoaluminophosphates for propene adsorption is reported by López et al. [22]. The promising performance of beta and ZSM-5 zeolites and SAPO-5 under cold start conditions are evidenced in this paper for the single hydrocarbon considered.

Other investigations have been conducted in real conditions, using a zeolite based HC trap located at the exhaust of a gasoline engine $[23,24]$. These studies have provided useful indication regarding the behaviour of selected materials towards the overall gas effluent, without discerning the effect of the adsorbent material on individual HCs.

The aim of the present paper was to study the adsorption properties of various zeolitic materials towards different HCs, taking into consideration those compounds which need to be recovered in petrochemical applications, such as light paraffins, or removed from the engine exhaust of light-duty gasoline vehicles, typically C2-C5 paraffins and olefins, plus monoring aromatic compounds [25]. Because of the variety of HCs considered, zeolites with pore opening ranging from 5 to $7.4 \AA$ (HZSM-5, silicalite and HY) were examined. Preliminary adsorption isotherms were acquired on dehydrated zeolites to obtain a basic characterization in saturation conditions at room temperature. The study of trapping capability was carried out by dynamic tests in a flow microreactor at temperature, partial pressures, and space velocity values compatible with the applications considered (298-523 K, $0.1 \mathrm{kPa}, 30000 \mathrm{~h}^{-1}$, resp.). The zeolites were not thermally treated before these tests, in order to evaluate their performance in real conditions. This approach permitted not only the acquisition of experimental data regarding adsorption equilibria but also obtaining indications regarding the adsorption rate and removal efficiency of different hydrocarbons on three zeolitic materials (both single compound and mixtures) in $\mathrm{HC}$ trap conditions.

\section{Experimental}

2.1. Materials. All adsorption measurements presented in this paper were performed on HZSM-5, silicalite, and HY in powder form (Zeolyst International). The main characteristics of these zeolitic materials are reported in Table 1. HZSM5 is the acidic form of ZSM-5 and is a well-known material widely used as a catalyst in chemical industry. It is characterised by a MFI (Mobil Five) three-dimensional channel system with pore openings of 5-6 $\mathrm{A}$, responsible for surface area and pore volume values of $405 \mathrm{~m}^{2} / \mathrm{g}$ and $0.24 \mathrm{~cm}^{3} / \mathrm{g}$, respectively. Silicalite has the same MFI crystalline structure of ZSM-5, therefore the same microchannel system, but no $\mathrm{Al}$ atoms in the framework. HY zeolite is characterised by a faujasite type structure having channels with pore opening of $7.4 \AA$ and containing $\mathrm{H}^{+}$as a countercation. Its surface area and pore volume are $730 \mathrm{~m}^{2} / \mathrm{g}$ and $0.51 \mathrm{~cm}^{3} / \mathrm{g}$, respectively. 
TABle 2: Composition and sources of hydrocarbon mixtures used for adsorption tests (provided by Praxair).

\begin{tabular}{lcr}
\hline Mixture $\mathrm{HC} / \mathrm{N}_{2}$ & Composition of individual HC, ppm & Total concentration, C3 ppm \\
\hline Ethylene $/ \mathrm{N}_{2}$ & 1280 & 853 \\
\hline Isobutene $/ \mathrm{N}_{2}$ & 643 & 857 \\
\hline Toluene $/ \mathrm{N}_{2}$ & 358 & 835 \\
\hline & n-Butane: 123 & 847 \\
& Isobutane: 128 & \\
C4-C5 alkanes $^{\mathrm{a}} / \mathrm{N}_{2}$ & n-Pentane: 105 & \\
& Isopentane: 102 & \\
& Neopentane: 100 & \\
\hline Isobutane-isobutene $/ \mathrm{N}_{2}$ & C5: 102 & 858 \\
\hline
\end{tabular}

${ }^{a}$ Equimolar mixture (as C3) of n-butane, isobutane, n-pentane, isopentane, and neopentane.

${ }^{\mathrm{b}}$ Equimolar mixture (as C3) of isobutane and isobutene.

While petrochemical applications require the removal of light paraffins and olefins, the HCs present in engine exhaust gases comprise paraffins, olefins, and aromatics of various molecular weights in the range $\mathrm{C} 1-\mathrm{C} 11$. In Table 2 the details of used mixtures are reported, with the specifications of their composition. The adsorption measurements were firstly carried out using mixtures of individual hydrocarbons in nitrogen. In particular, three hydrocarbons were identified as a representative of the major species present in the engine exhaust during cold start (ethylene, isobutene, and toluene) [25]. The adsorption isotherms were carried out on these three selected hydrocarbons, while all the mixtures reported in Table 2 were used for the tests in flow microreactor at atmospheric pressure. A mixture of $\mathrm{C} 4-\mathrm{C} 5$ alkanes (nbutane, i-butane, n-pentane, i-pentane, and neopentane) was tested to study the competitive adsorption between some selected light paraffins, while a mixture of isobutane and isobutene was selected to have indications about the possible interactions between paraffins and olefins during the adsorption phenomena on zeolites. Taking into account that the adsorption capacity of zeolites is mainly due to a pore filling mechanism, the concentration of each hydrocarbon was selected in order to have mixtures with the same total concentration in terms of carbon atoms. This allowed for comparable carbon mass flow rates in different molecular structures. As propane mixtures were used for calibration of the $\mathrm{HC}$ analyzer (see Section 2.3), the total concentration was expressed in terms of $\mathrm{C} 3$ and resulted in about $850 \mathrm{ppm}$ for all mixtures (corresponding to about $0.1 \mathrm{kPa}$, approximately the actual partial pressure of HCs in the engine exhaust). Within each mixture the same number of moles in terms of $\mathrm{C} 3$ was present for each hydrocarbon.

2.2. Adsorption Isotherms Procedure. Adsorption isotherms at room temperature were obtained by a gravimetric technique and performed with the apparatus sketched in Figure 1 [26]. This is a McBain-type adsorption balance, equipped with a quartz spring (Ruska Instrument Co., Houston, Texas), whose elongation law is known. A small quartz pan, containing the adsorbent material, hooked to the spring, enables the evaluation of the amount of adsorbate by measuring spring elongation with the help of a cathetometer. Equilibrium gas pressure was measured through electronic devices (Edwards Datametrics 1500). A Heto thermostating unit allowed a temperature control within the range of $\pm 0.1 \mathrm{~K}$. Before measurement samples were thermally activated at $623 \mathrm{~K}$ under high vacuum $\left(P<10^{-6} \mathrm{kPa}\right)$ by means of an Edwards turbomolecular pump for 3 hours using a toroidal furnace, after cooling to $298 \mathrm{~K}$ aliquots of gas were allowed from time to time to enter the balance chamber and sufficient time was awaited to attain equilibrium. Adsorption isotherms were outlined by plotting the amounts of adsorbate on dry basis versus gas partial pressures at equilibrium.

The gravimetric tests were affected at room temperature for the three selected HCs (ethylene, isobutene, and toluene) in order to obtain a basic characterization of the three zeolitic materials in terms of equilibrium adsorption capacity towards compounds representative of the main $\mathrm{HC}$ families that need to be captured in the applications considered.

2.3. Adsorption Kinetics Procedure. The breakthrough curves were performed by the experimental apparatus shown in Figure 2. A fixed bed microreactor, constituted by a stainless steel tube of $10 \mathrm{~mm}$ i.d., was inserted in a tubular electric oven equipped with a temperature controller. The reactor was loaded with zeolites in powder form $(1 \mathrm{~g}, 180-350 \mu \mathrm{m})$. The gas flow rate $(1 \mathrm{l} / \mathrm{min})$ was selected to realise a space velocity value (gas gravimetric flow rate/adsorbent weight) of $30000 \mathrm{~h}^{-1}$ that is representative of conditions occurring at the engine exhaust on TWC during automotive start-up phase.

An online analyzer equipped with flame ionisation detector (Siemens Fidamat 5 E-AP) was used for hydrocarbon concentration analysis before and after the adsorbent bed.

These tests were effected at different temperature values (from $298 \mathrm{~K}$ to TWC light off values) and low hydrocarbon partial pressures $(0-1 \mathrm{kPa})$, which are usually encountered in engine exhaust gases.

The breakthrough curves were constructed reporting hydrocarbon concentrations measured at the outlet of 


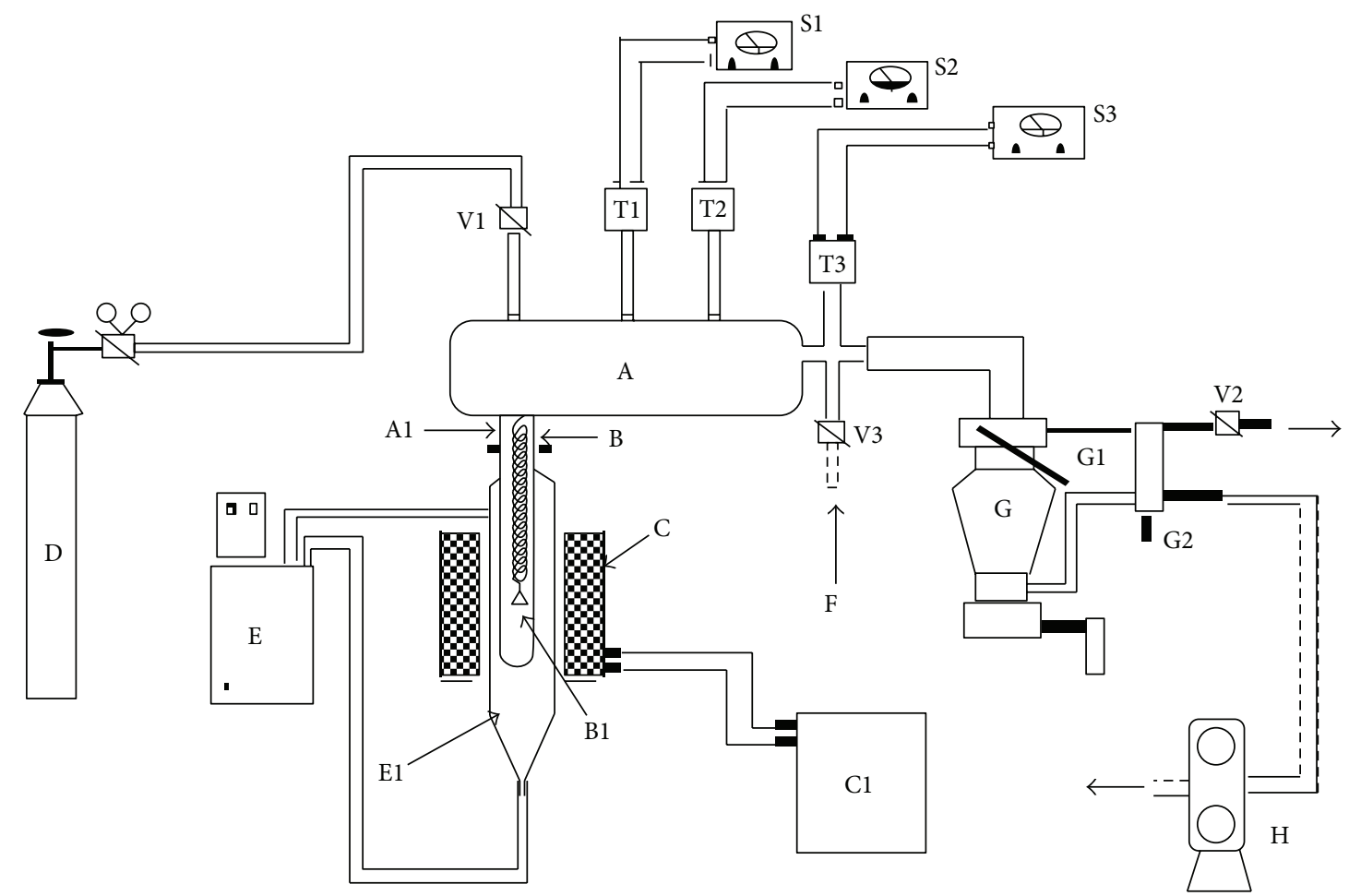
(A) Balance chamber
(A1) Quartz spring zone
(B) Quartz spring
(B1) Pan
(C) Toroidal oven for sample activation
(C1) Oven programmer
(D) Cylinder of $\mathrm{N}_{2}$ for chamber purge
(E) Thermostatic unit
(E1) Water jacket
(F) Gas inlet

(G) Diffusion pump

(G1) Baffle valve

(G2) Backing/roughing valve

(H) Rotary pump

(S1, S2, and S3) Pressure indicators

(T1, T2, and T3) Pressure transducers

(V1) Purge inlet valve

(V2) Purge outlet valve

(V3) Needle valve

FIGURE 1: Scheme of the experimental apparatus used for measurements of equilibrium isotherms by gravimetric tests.

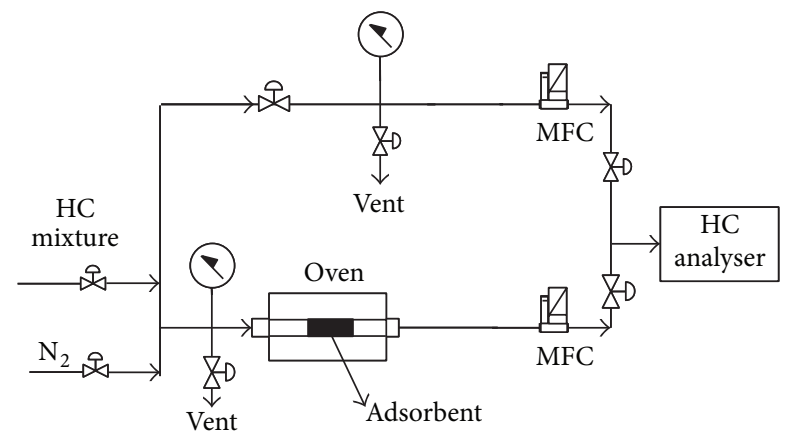

FIGURE 2: Scheme of the experimental apparatus used for measurements of adsorption properties by flow microreactor.

the adsorbent bed as function of time on stream. These concentrations were acquired in terms of $\mathrm{C} 3$, since the analyzer calibration was affected by using propane mixtures (see Section 2.1). From these curves the values of hydrocarbon cumulative adsorption were calculated as mass of adsorbed $\mathrm{HC}$ per $100 \mathrm{~g}$ of zeolite (wt\%), according to the following formula:

$$
\frac{\mathrm{g}_{\mathrm{HC}}}{100 \mathrm{~g}_{\text {zeolite }}}=\sum_{i=1}^{n}\left[\left(C_{\mathrm{in}}-C_{i}\right)\left(t_{i}-t_{i-1}\right)\right] \mathrm{QM}_{\mathrm{C} 3 \mathrm{H} 8} 100,
$$

where $C_{\text {in }}$ is the $\mathrm{HC}$ concentration (expressed as C3) at the reactor inlet, $C_{i}$ is the $\mathrm{HC}$ concentration at the reactor outlet at the time $t_{i}, n$ is the generic instant of concentration acquisition, $Q$ is volumetric flow rate of the gas stream in $\mathrm{Nl} / \mathrm{min}$, and $M_{\mathrm{C} 3 \mathrm{H} 8}$ is the molecular weight of propane. These percentage cumulative values were used for presentation of experimental results relative to dynamic tests described in the next section.

The zeolitic materials were tested in all flow adsorption runs without any preliminary thermal treatment, in order to simulate the utilization conditions of a $\mathrm{HC}$ trap at the engine exhaust. In this way each material retained its intracrystalline water content when it was exposed to hydrocarbon gas stream. 
TABLE 3: Equilibrium adsorption capacities (wt\%) obtained at $298 \mathrm{~K}$ by gravimetric tests at saturation and $0.1 \mathrm{kPa}$ for different HCs on HZSM5, silicalite, and HY.

\begin{tabular}{lcccccc}
\hline \multirow{2}{*}{ Zeolite } & \multicolumn{2}{c}{ Ethylene } & \multicolumn{2}{c}{ Isobutene } & \multicolumn{2}{c}{ Toluene } \\
& Saturation & $0.1 \mathrm{kPa}$ & Saturation & $0.1 \mathrm{kPa}$ & Saturation & $0.1 \mathrm{kPa}$ \\
\hline HZSM-5 & 7.2 & 3.8 & 8.1 & 5.7 & 12.8 & 8.0 \\
Silicalite & 6.8 & 2.3 & 11.5 & 8.7 & 13.8 & 7.7 \\
HY & 5.4 & 1.6 & 22.5 & 14.8 & 7.1 \\
\hline
\end{tabular}

TABLE 4: Adsorption capacities (wt\%) derived by breakthrough curves at various temperature values for different HCs on HZSM-5, silicalite, and HY. HC partial pressure: $0.1 \mathrm{kPa}$, space velocity: $30000 \mathrm{~h}^{-1}$.

\begin{tabular}{|c|c|c|c|c|c|c|}
\hline Zeolite & $T, \mathrm{~K}$ & Ethylene & Isobutene & Toluene & $\begin{array}{l}\text { Isobutene } \\
\text { Isobutane }\end{array}$ & C4-C5 paraffins \\
\hline \multirow{8}{*}{ HZSM-5 } & 298 & 0.5 & 2.2 & 4.0 & 4.1 & 1.7 \\
\hline & 348 & - & 3.7 & 2.9 & 5.4 & 0.8 \\
\hline & 373 & 0 & 4.5 & - & 5.4 & 0.2 \\
\hline & 398 & - & - & 1.4 & - & - \\
\hline & 413 & - & 4.6 & - & 4.0 & - \\
\hline & 423 & - & - & 1.0 & - & - \\
\hline & 463 & - & 2.4 & - & 1.6 & - \\
\hline & 523 & - & 0.6 & - & - & - \\
\hline \multirow{3}{*}{ Silicalite } & 298 & 0.2 & 1.1 & 5.0 & & 0.3 \\
\hline & 373 & 0 & 0.5 & 2.5 & - & - \\
\hline & 423 & 0 & 0.1 & 1.6 & - & - \\
\hline \multirow{6}{*}{$\mathrm{HY}$} & 298 & 0.04 & 2.8 & 6.8 & - & 0.7 \\
\hline & 348 & - & - & - & - & 0.2 \\
\hline & 353 & - & 6.3 & - & - & - \\
\hline & 373 & 0 & - & 5.2 & - & 0.1 \\
\hline & 403 & - & 4.5 & - & - & - \\
\hline & 423 & 0 & - & 2.1 & - & - \\
\hline
\end{tabular}

\section{Results and Discussion}

In Table 3 the equilibrium adsorption capacities in wt $\%$ for ethylene, isobutene, and toluene as measured at room temperature in gravimetric tests are summarized for the three zeolitic materials. In Table 4 the adsorption capacities of all hydrocarbons investigated, derived by breakthrough curves and calculated by (1), are reported for temperature values ranging from 298 to $523 \mathrm{~K}$, at partial pressure of $0.1 \mathrm{kPa}$ and space velocity of $30000 \mathrm{~h}^{-1}$.

3.1. Adsorption Measurements at Room Temperature. In Figure 3 adsorption isotherms under equilibrium conditions of ethylene, isobutene, and toluene at $298 \mathrm{~K}$ on HZSM-5 are compared. A magnification of the low pressure zone (0$0.1 \mathrm{kPa})$ is reported on the top right. All curves show the typical shape of the adsorption isotherms on microporous solids [27].

Increasing pressure gave rise to a sharp weight increase for toluene, because of the capillary condensation phenomena occurring when the saturation vapor pressure of toluene $(3 \mathrm{kPa}$ at $298 \mathrm{~K})$ was approached [28]. As regards ethylene and isobutene, the saturation conditions occurred at higher pressures. At $53 \mathrm{kPa}$ (out of Figure 3, but reported in Table 3) the amounts of ethylene and isobutene adsorbed on HZSM-5 expressed in wt\% resulted in 7.2 and $8.1 \%$, respectively. Ethylene, isobutene, and toluene exhibited adsorption capacity relatively high even at low pressure; that is, more than $50 \%$ of the maximum amount at saturation was adsorbed at a pressure of $0.1 \mathrm{kPa}$ (Table 3 ).

The breakthrough curves were used to calculate the cumulative values of adsorption capacity as a function of time (equation (1)). Figure 4 reports the results obtained with ethylene, isobutene, and toluene on HZSM-5 at $298 \mathrm{~K}$ and $30,000 \mathrm{~h}^{-1}$. The maximum adsorption capacity was obtained with toluene (3.97\%, Table 4), for which bed saturation was reached after about 50 minutes. As regards isobutene an adsorption capacity of $2.2 \%$ was obtained, with a faster decay of zeolite trapping capability. Ethylene adsorption was very poor, as the bed saturation was reached after only 4 minutes and the adsorption capacity did not exceed $0.5 \%$. The removal efficiency of the zeolite adsorbent bed, defined as $1-C_{i} / C_{\text {in }}$, was used as indicator of adsorption kinetics and was derived by slopes of the cumulative adsorption curves. In particular, the magnification shown in Figure 4 shows that slopes of about $0.18 \mathrm{~g}_{\mathrm{HC}} / \mathrm{min} / 100 \mathrm{~g}_{\mathrm{ZEO}}$ (corresponding to unitary removal efficiency) were reached for toluene and isobutene on HZSM-5 at room temperature during the first 5 


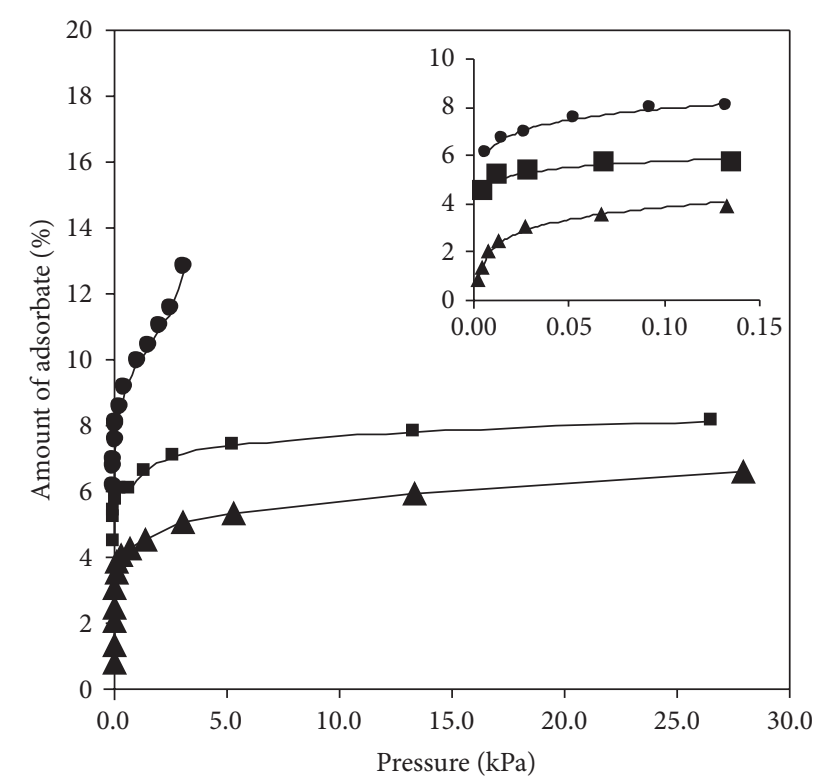

Figure 3: Adsorption isotherms at $298 \mathrm{~K}$ of ethylene ( $\mathbf{\Delta})$, isobutene $(\boldsymbol{\square})$, and toluene $(\bullet)$ on HZSM-5.

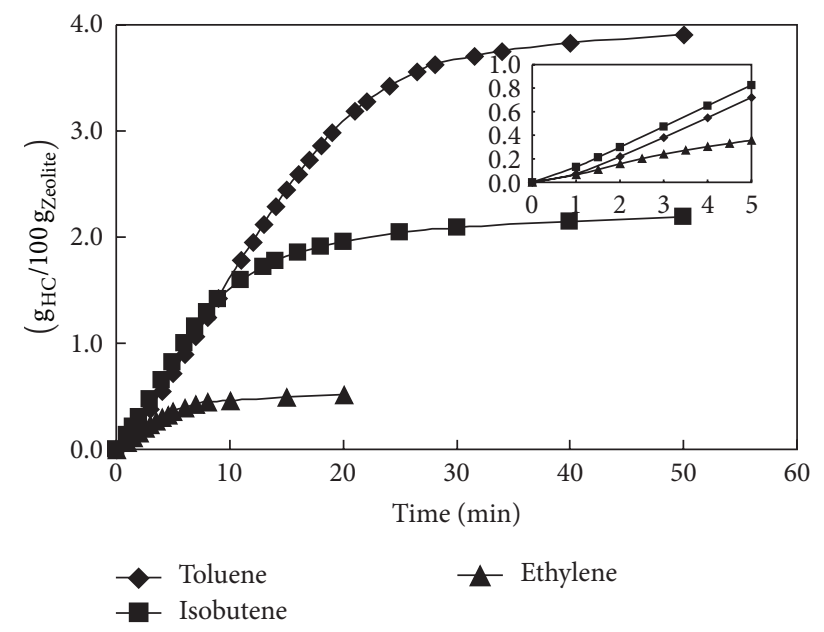

FIgURE 4: Cumulative adsorption of ethylene, isobutene, and toluene on HZSM-5 adsorbent bed versus time on stream at $298 \mathrm{~K}$ and $30,000 \mathrm{~h}^{-1}$.

minutes, which normally include the time range necessary to reach the TWC light-off temperature. In the same time range the removal efficiency for ethylene resulted at least $50 \%$ less.

In the hypothesis that adsorption of the three hydrocarbons on HZSM-5 at $298 \mathrm{~K}$ is essentially due to physical interaction between gas molecule and solid surface (van der Waals interaction) the low adsorption capacity exhibited by HZSM-5 for ethylene can be attributed to the absence in the molecule of any permanent dipole moment that implies a weaker contribution of coulombic forces to the overall van der Waals interaction [27]. The higher trapping capability for toluene can be explained considering the larger molecular size with respect to the other two hydrocarbons. In fact, for a larger molecule the enhancement of the interaction energy,

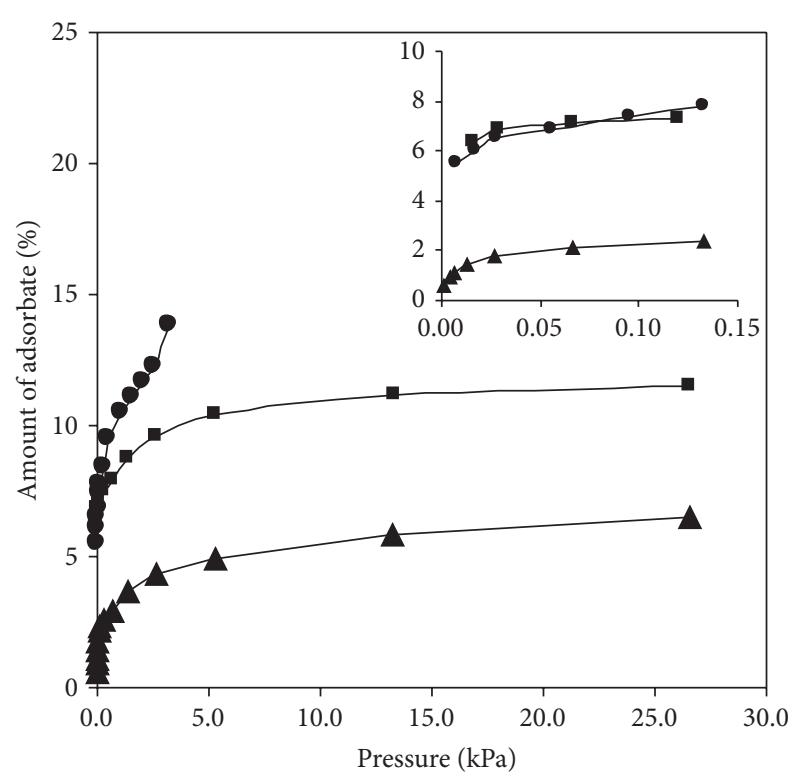

FIGURE 5: Adsorption isotherms at $298 \mathrm{~K}$ of ethylene ( $\mathbf{\Delta})$, isobutene $(\mathbf{\square})$, and toluene $(\bullet)$ on silicalite.

due to the overlap of the adsorption field from neighboring walls, can be expected in very fine pores [27].

In order to investigate the influence of $\mathrm{Si} / \mathrm{Al}$ ratio on adsorption capacities, measurements on silicalite, a zeolite isostructural of ZSM-5 and Al-free, were performed. The comparison between adsorption isotherms of ethylene, isobutene, and toluene at $298 \mathrm{~K}$ on silicalite is shown in Figure 5. In saturation conditions no significant difference was observed for ethylene and toluene adsorption (Table 3), where a strong increase was detected for isobutene with respect to HZSM-5. Considering in particular the low pressure range $(0-0.1 \mathrm{kPa}$, top right figure) a slight reduction of adsorption capacities for ethylene and toluene was observed, while also in these conditions the adsorption of isobutene resulted in being higher on silicalite than on HZSM-5. The absence of $\mathrm{Al}$ reduces the number of adsorption sites and, as a consequence, the intensity of adsorbate-adsorbent interaction energy, responsible for adsorption phenomena. This can explain the adsorption reduction observed for ethylene and toluene on silicalite at low partial pressure. Regarding ethylene a further contribution to uptake on HZSM-5 can be caused by reactivity phenomena [18].

The lower adsorption capacity observed in gravimetric tests for isobutene on HZSM-5 with respect to silicalite (Figures 3 and 5) can be attributed to a chemical adsorption contribution resulting from the interaction of $\mathrm{C}=\mathrm{C}$ double bond with the acid sites of HZSM-5 (highly active Brönsted acid sites) [29]. This implies that under conditions reached in gravimetric tests on dehydrated zeolites some oligomer species can be formed on HZSM-5, with partial blockage of micropore opening and consequent limitation of adsorption capacity. 


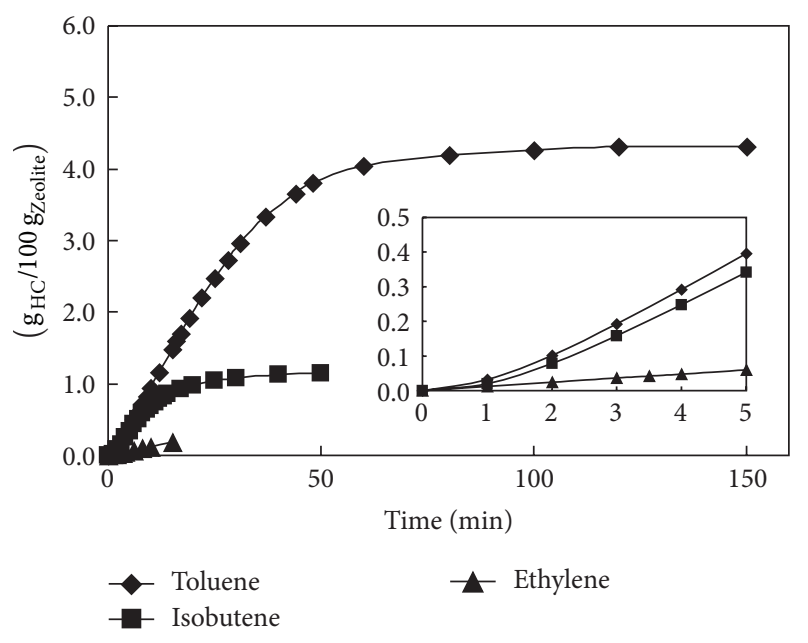

FIGURE 6: Cumulative adsorption of ethylene, isobutene, and toluene on silicalite adsorbent bed versus time on stream at $298 \mathrm{~K}$ and $30,000 \mathrm{~h}^{-1}$.

In measurements affected under dynamic conditions (Figure 6 and Table 4), a global reduction of trapping capability was observed on silicalite with respect to HZSM-5. In particular, adsorption of ethylene was negligible, while a 50\% decrease was observed for isobutene adsorption.

It is possible to hypothesize that the presence of water intracrystalline inside the zeolites tested by dynamic experiments hindered the oligomerization phenomena and made prevalent the effect of the adsorption sites number associated with the presence of $\mathrm{Al}$ in the MFI framework, determining higher adsorption capacities of isobutene on HZSM5. Saturation uptake for toluene was comparable to that obtained on HZSM-5, but the process turned out slower, with bed saturation being reached after about 150 minutes. On the other hand, the adsorption rate during the first minutes was lower on silicalite with respect to HZSM-5 for both isobutene and toluene (the maximum slope did not exceed $0.11 \mathrm{~g}_{\mathrm{HC}} / \mathrm{min} / 100 \mathrm{~g}_{\mathrm{ZEO}}$, corresponding to a removal efficiency of about 0.6). Also this behavior can be correlated to lower number of adsorption sites in silicalite, hypothesizing that molecule diffusion through the microchannels is retarded in the absence of strength adsorption fields.

The influence of structure type on adsorption capacities was analyzed by adsorption measurements on $\mathrm{HY}$, a faujasitetype zeolite, with the same $\mathrm{Si} / \mathrm{Al}$ ratio of ZSM-5. Adsorption isotherms of ethylene, isobutene, and toluene at $298 \mathrm{~K}$ on $\mathrm{HY}$ are reported in Figure 7. Also in the case of HY the affinity for ethylene resulted very low. On the contrary, a very high adsorption capacity was shown on $\mathrm{HY}$ for isobutene (at a pressure of $0.1 \mathrm{kPa}$ was already about $15 \%$, as reported in Table 3). In particular, this zeolite adsorbed more isobutene than toluene, and the amount of adsorbed isobutene was also larger than that observed on HZSM5 and silicalite, for all pressure values. This result can be explained considering the greater chemical reactivity of $\mathrm{C}=\mathrm{C}$ double bond of isobutene with respect to ethylene [30]. As recalled before chemisorption phenomena involving acidic

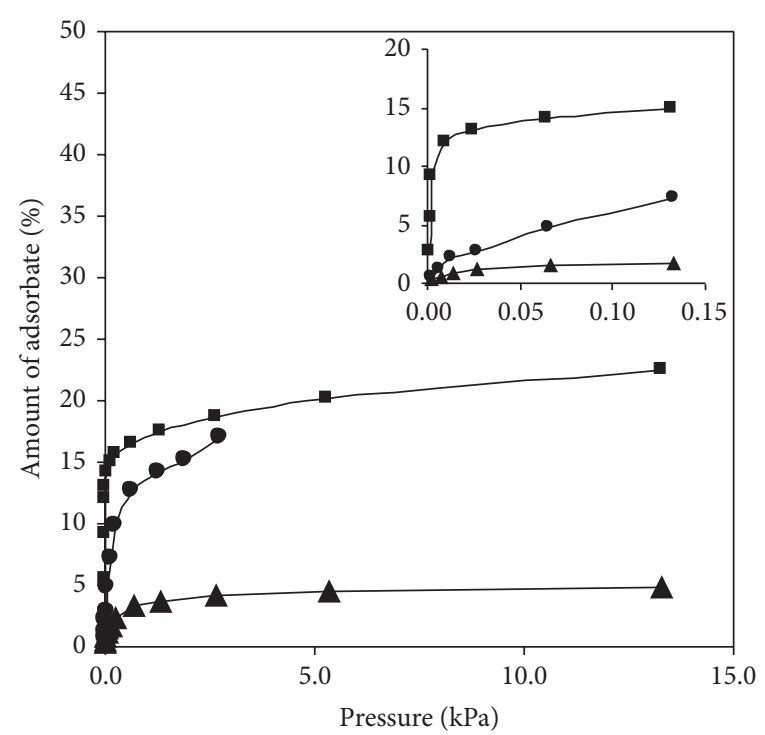

FIGURE 7: Adsorption isotherms at $298 \mathrm{~K}$ of ethylene ( $\mathbf{\Delta})$, isobutene $(\boldsymbol{\square})$, and toluene ( $)$ on HY.

zeolites and unsaturated hydrocarbons are likely due to an oligomerisation process of alkenes [29]. According to this hypothesis it is possible to distinguish two cases:

(a) for HZSM-5, having pore opening of 5-6 $\AA$, a poremouth blocking occurs because of the production of isobutene oligomerisation, with the subsequent reduction of adsorption capacity compared to silicalite, as reported above;

(b) in the case of HY, having a pore opening (7.4 $\AA$ ) larger than HZSM-5, oligomerisation process of isobutene proceeds in parallel with the adsorption and stops only when the free volume inside the zeolite is filled with the oligomer products.

The results of flow experiments on HY at $298 \mathrm{~K}$ are reported in Figure 8. Adsorption of ethylene on HY zeolite was negligible, while a strong uptake was detected for isobutene and toluene. The adsorbed amount of these two hydrocarbons turned out about 1.5 times greater on HY than on HZSM-5, due to the larger micropore volume of HY. However, unlike the gravimetric test, under flow conditions the uptake of toluene was much larger than isobutene. It should be taken into account that in flow experiments the adsorbent material was tested without any preliminary thermal treatment; thus, the oligomerisation phenomena inside the microchannels could be affected by the presence of intracrystalline water molecules. The behavior of HY in flow adsorption experiments can be explained hypothesizing that the contribution of physical adsorption is predominant with respect to chemisorption.

The flow tests also evidenced that on HY the adsorption rate was lower than on HZSM-5 during the first 5 minutes and comparable to that observed on silicalite (i.e., the slope of toluene curve did not exceed $\left.0.10 \mathrm{~g}_{\mathrm{HC}} / \mathrm{min} / 100 \mathrm{~g}_{\mathrm{ZEO}}\right)$. The effect of minor energy of adsorption fields can be invoked to 


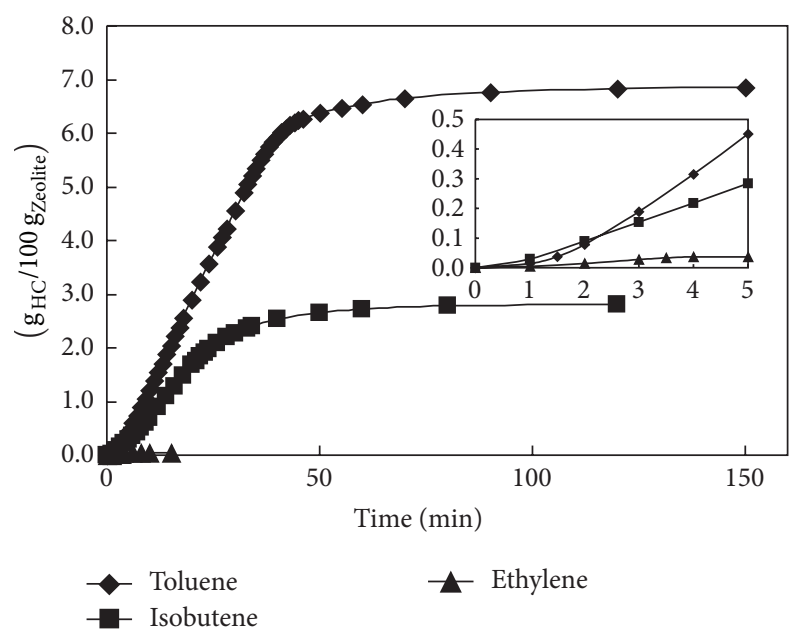

FIGURE 8: Cumulative adsorption of ethylene, isobutene and toluene on HY adsorbent bed versus time on stream at $298 \mathrm{~K}$ and $30,000 \mathrm{~h}^{-1}$.

explain this phenomenon. In fact, in spite of $\mathrm{Al}$ presence in the framework, the larger micropore diameter of HY makes the interaction energy undergone by hydrocarbon molecules weaker [27].

The above results evidence that the adsorption capacities calculated by breakthrough curves were always lower with respect to the values obtained by gravimetric tests. Taking into account that the zeolite microchannels contained intracrystalline water molecules during flow adsorption runs (see Section 2); these lower adsorption capacities can be attributed to the competition inside the zeolite microchannels between intracrystalline water and $\mathrm{HC}$ adsorbate.

3.2. The Effect of Temperature on HC Trapping. The breakthrough curves were determined at various temperatures in the range $298-523 \mathrm{~K}$ in order to determine adsorption properties in conditions simulating the engine warm-up phase. As regards ethylene the already scarce adsorption observed at $298 \mathrm{~K}$ on HZSM- 5 became negligible at $373 \mathrm{~K}$ confirming that this material is not suitable for trapping this type of hydrocarbon at low partial pressure. Further, no adsorption was detected for ethylene on HY and silicalite also at higher temperatures.

The adsorption of toluene on HZSM-5 as function of temperature is shown in Figure 9.

The trapping capability progressively decreased raising the temperature up to $423 \mathrm{~K}$, but an appreciable adsorption was measured also at the highest temperature investigated $(1 \%$ at $423 \mathrm{~K})$. The decrease of the uptake capacity when temperature is raised is expected, being adsorption of an exothermic process, and indicates that interaction between toluene and HZSM-5 at low partial pressure is of physical nature. Similar behaviors were observed for toluene on silicalite (Figure 10) and HY (Figure 11) when temperature was raised from 298 to $423 \mathrm{~K}$. In particular, at $423 \mathrm{~K}$ the adsorption of toluene on silicalite and HY was reduced of about $70 \%$.

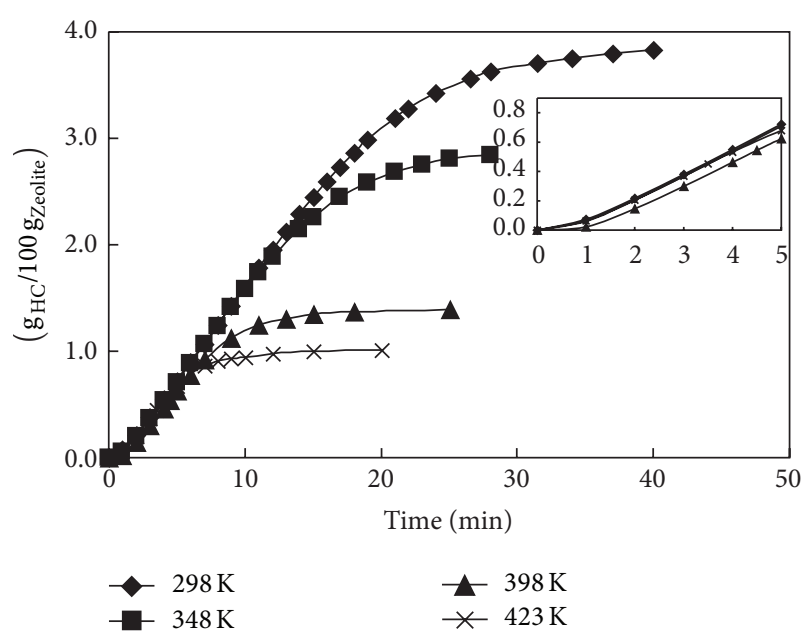

FIGURE 9: Cumulative adsorption of toluene on HZSM-5 adsorbent bed versus time on stream at $30,000 \mathrm{~h}^{-1}$ and different temperature values.

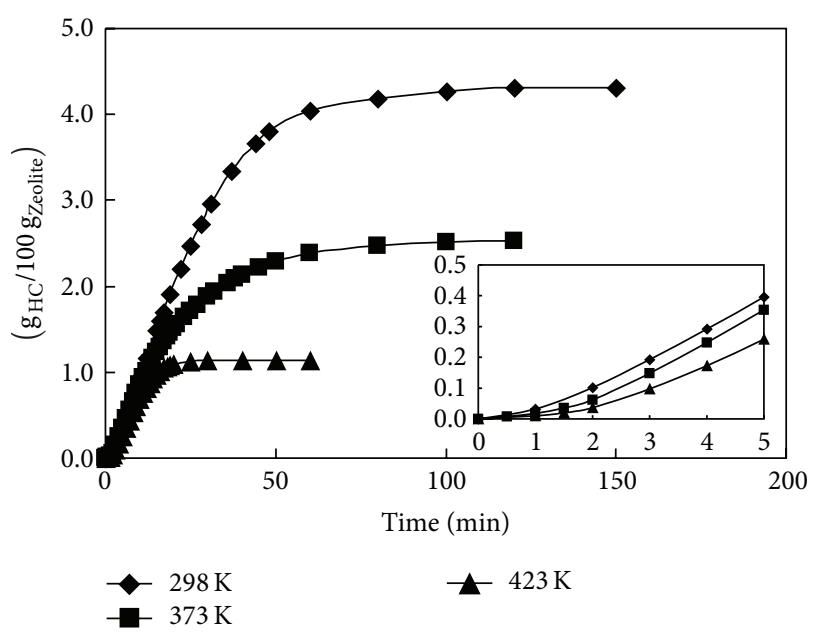

FIGURE 10: Cumulative adsorption of toluene on silicalite adsorbent bed versus time on stream at $30,000 \mathrm{~h}^{-1}$ and different temperature values.

Regarding the adsorption rate no significant effect of temperature was detected, in particular an almost unitary efficiency (slope close to $0.18 \mathrm{~g}_{\mathrm{HC}} / \mathrm{min} / 100 \mathrm{~g}_{\mathrm{ZEO}}$ ) was detected on HZSM- 5 at all temperatures up to $423 \mathrm{~K}$ during the first 5 minutes.

A particular behavior was observed for isobutene adsorption when temperature was increased. Increased uptakes were found on HZSM-5 (Figure 12) from 298 to $413 \mathrm{~K}$ (4.55\%), with removal efficiency practically unitary, whereas a smaller amount was adsorbed for higher temperature up to $523 \mathrm{~K}$ $(0.63 \%)$, with slower adsorption rate.

Activated physical adsorption can occur in microporous solids when the width of the pores is very close to the diameter of the adsorbate molecule, since in this case the molecule encounters an energy barrier to its passage through the constriction [27]. This effect cannot be invoked for adsorption of isobutene on HZSM-5 from 298 to $413 \mathrm{~K}$, 


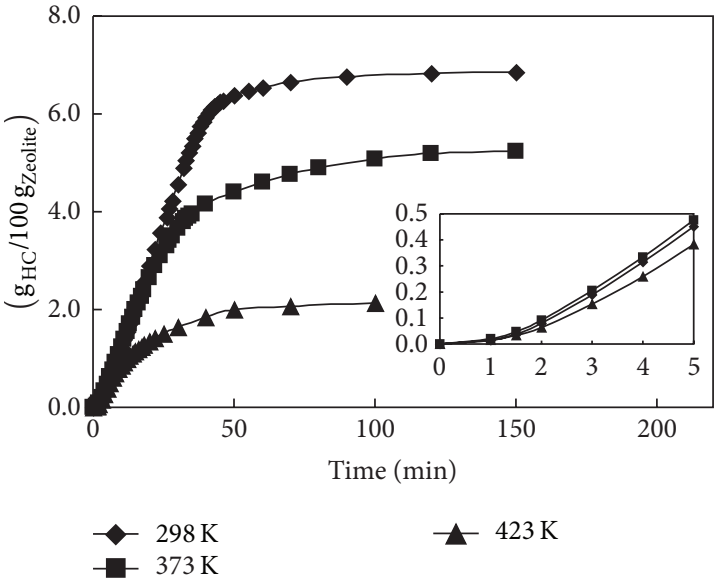

FIGURE 11: Cumulative adsorption of toluene on HY adsorbent bed versus time on stream at $30,000 \mathrm{~h}^{-1}$ and different temperature values.

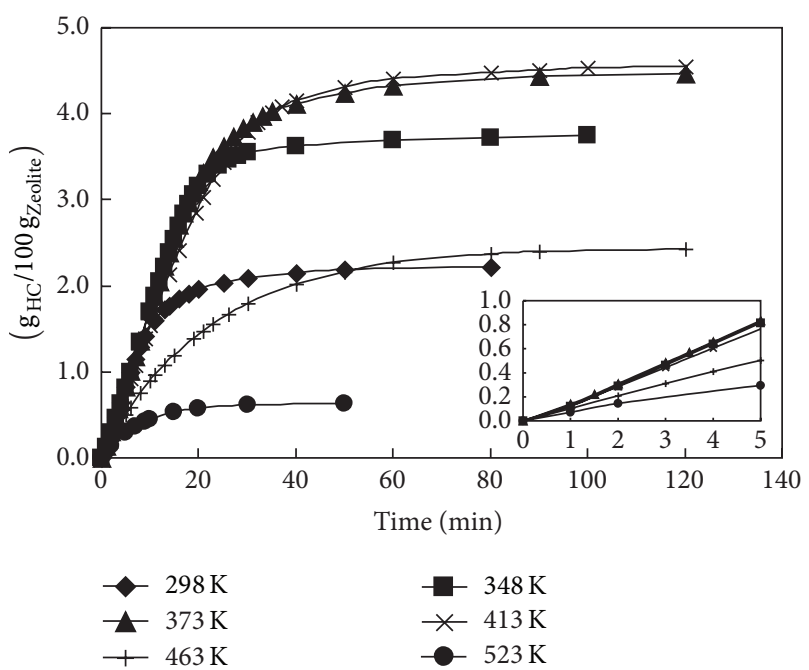

FIgURE 12: Cumulative adsorption of isobutene on HZSM-5 adsorbent bed versus time on stream at $30,000 \mathrm{~h}^{-1}$ and different temperature values.

because this molecule has a diameter inferior to that of toluene and does not involve any physical activation effect with temperature. Then a contribution of chemical adsorption can be taken into account to explain the results obtained for isobutene in flow experiments. On the other hand the greater stability of aromatic unsaturation, compared to that due to the $\mathrm{C}=\mathrm{C}$ double bond of isobutene, can give reason of the absence of chemical activation in the case of toluene.

As regards silicalite (Figure 13) the already scarce adsorption capacity observed for isobutene at $298 \mathrm{~K}$ became negligible at higher temperatures, while the adsorption rate slightly decreased, confirming the role of framework $\mathrm{Al}$ on the physical adsorption interaction energy. On the contrary, the effect of chemical activation made the uptake capacity of isobutene on HY (Figure 14) at 353 and $403 \mathrm{~K}$ about 2 and 1.5 times higher than at $298 \mathrm{~K}$, respectively, while no improvement was observed regarding the removal

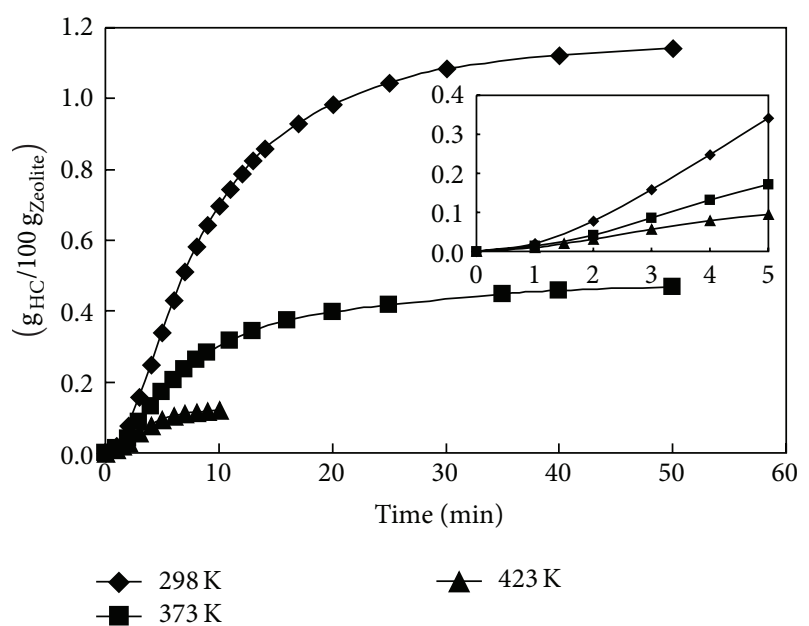

FIGURE 13: Cumulative adsorption of isobutene on silicalite adsorbent bed versus time on stream at $30,000 \mathrm{~h}^{-1}$ and different temperature values.

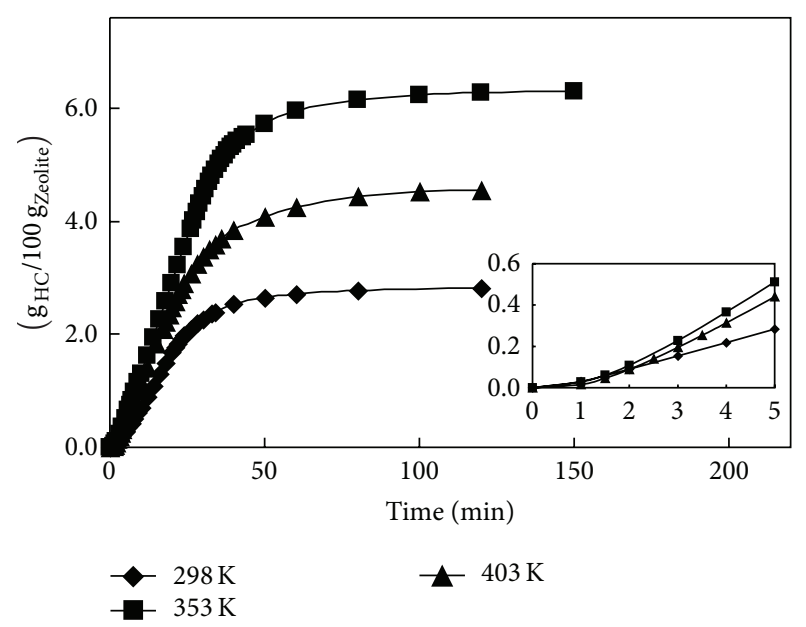

FIGURE 14: Cumulative adsorption of isobutene on HY adsorbent bed versus time on stream at $30,000 \mathrm{~h}^{-1}$ and different temperature values.

efficiency during the first 5 minutes. The results of Figures 12-14 confirm the hypothesis of the chemical contribution to isobutene adsorption and suggest a correlation between this contribution and the $\mathrm{Si} / \mathrm{Al}$ ratio.

The adsorption affinity of HZSM-5 towards paraffins is shown by curves of Figure 15, which refer to an equimolar mixture of $\mathrm{C}_{4}-\mathrm{C}_{5}$ paraffins (n-butane, isobutane, $\mathrm{n}$-pentane, isopentane, and neopentane, total $\mathrm{C}_{3}$ concentration of $850 \mathrm{ppm}$ ). Both uptake capacity and adsorption rate rapidly decreased increasing the temperature, becoming negligible already at $373 \mathrm{~K}$. A very low affinity for paraffins was also observed on silicalite and HY (Table 4). The results for HY are reported in Figure 16; it can be noted that already at $298 \mathrm{~K}$ the adsorption capacity at bed saturation is only $0.73 \%$.

The role of olefin double bond and the low affinity towards paraffins was confirmed by the curves shown in Figure 17, where the results of flow tests for an equimolar mixture 


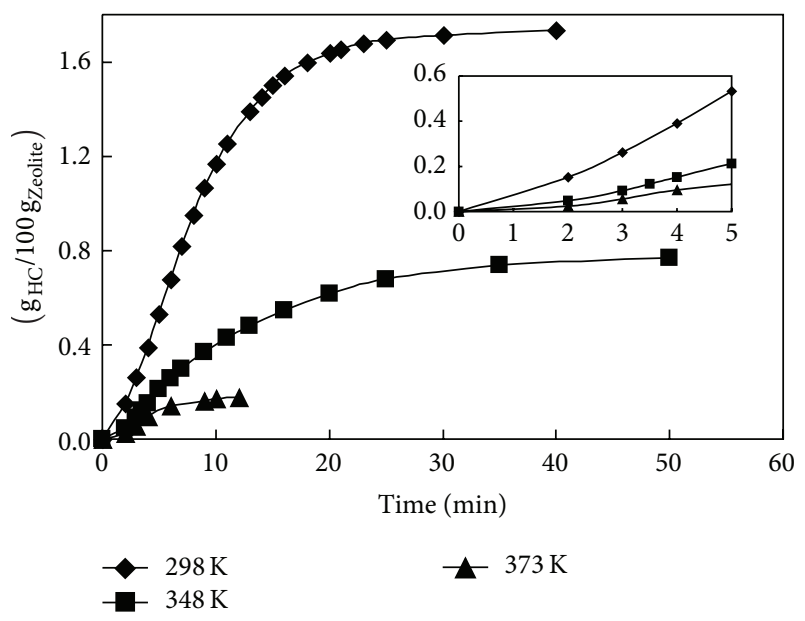

FIgURE 15: Cumulative adsorption of $\mathrm{C}_{4}-\mathrm{C}_{5}$ paraffin mixture on HZSM-5 adsorbent bed versus time on stream at $30,000 \mathrm{~h}^{-1}$ and different temperature values. Reactor feed: n-butane, isobutane, $n$ pentane, isopentane, and neopentane equimolar mixture.

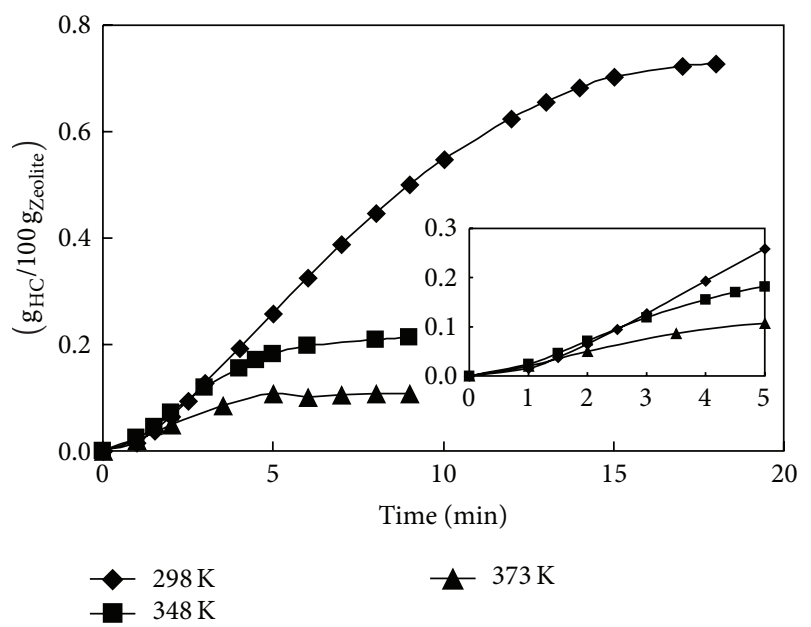

Figure 16: Cumulative adsorption of $\mathrm{C}_{4}-\mathrm{C}_{5}$ paraffin mixture on $\mathrm{HY}$ adsorbent bed versus time on stream at $30,000 \mathrm{~h}^{-1}$ and different temperature values. Reactor feed: n-butane, isobutane, n-pentane, isopentane, and neopentane equimolar mixture.

of isobutene and isobutane on HZSM-5 are reported. The adsorption of this mixture on HZSM-5 was higher than isobutene at temperature between 298 and $373 \mathrm{~K}$ (Figure 12 and Table 4), probably due to a synergic effect associated with isobutane alkylation by isobutene, favored on zeolite catalysts at low temperatures [30]. A reduction of bed trapping capacity was observed increasing the temperature, when the minor affinity of ZSM-5 towards the paraffin adsorption did not favor alkylation reactions. Only at room temperature the adsorption rate permitted high removal efficiency to be reached during the first minutes.

\section{Conclusions}

Three zeolitic materials (HZSM-5, silicalite, and HY) were studied as adsorbents for light hydrocarbon traps. Isotherm

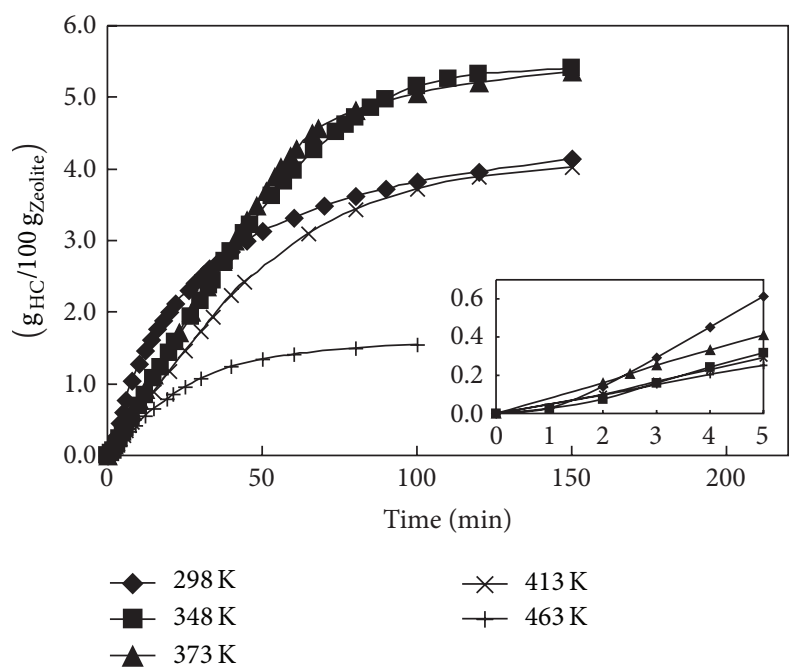

FIGURE 17: Cumulative adsorption of equimolar isobutane/isobutene mixture on HZSM-5 adsorbent bed versus time on stream at $30,000 \mathrm{~h}^{-1}$ and different temperature values.

gravimetric tests at room temperature were performed up to saturation pressure for ethylene, isobutene, and toluene, while dynamic tests in flow microreactor were carried out at low partial pressure $(0.1 \mathrm{kPa})$ and different temperature values (298-523 K) on the same three hydrocarbons plus two mixtures of C4-C5 paraffins and isobutane/isobutene.

The three adsorbents showed high affinity at room temperature for toluene and isobutene, but minor affinity for paraffins and ethylene. In particular the adsorption of ethylene was appreciable on HZSM-5, but resulted negligible for silicalite and HY. Equilibrium adsorption capacities obtained with breakthrough curves at $0.1 \mathrm{kPa}$ resulted in being very lower with respect to values reachable by gravimetric tests at the same partial pressure, due to the presence of intracrystalline water in zeolite samples.

Gravimetric tests and breakthrough curves evidenced chemisorption phenomena as regards isobutene adsorption on $\mathrm{Al}$ containing materials (HZSM-5 and HY), with possible formation of oligomeric species inside zeolite microchannels.

Increasing temperature from 298 up to $423 \mathrm{~K}$ adsorption capacity measured by dynamic tests for toluene on the three materials decreased while it became negligible for ethylene already at $373 \mathrm{~K}$ also on HZSM-5. As regarding isobutene a maximum in adsorption capacity was reached for HZSM-5 at $413 \mathrm{~K}$ and for $\mathrm{HY}$ at $353 \mathrm{~K}$. While the results obtained for ethylene and toluene could be interpreted in terms of physical adsorption, a chemical adsorption contribution was invoked to explain isobutene uptake increment with temperature.

Experiments affected with a C4-C5 paraffin mixture evidenced the minor affinity of the three materials towards saturated hydrocarbons. Breakthrough curves performed with isobutene-isobutane equimolar mixture evidenced the role of $\mathrm{C}=\mathrm{C}$ double bond on adsorption capacity of HZSM-5 towards hydrocarbons and the possible occurring of alkylation reactions. 


\section{Conflict of Interests}

The authors declare that there is no conflict of interests regarding the publication of this paper.

\section{References}

[1] F. Miano, "Adsorption of hydrocarbon vapour mixtures onto zeolite 5A," Colloids and Surfaces A: Physicochemical and Engineering Aspects, vol. 110, no. 1, pp. 95-104, 1996.

[2] C. Papaioannou, G. Petroutsos, and W. Gunßer, "Examination of the adsorption of hydrocarbons at low coverage on faujasite zeolites," Solid State Ionics, vol. 101-103, no. 1, pp. 799-805, 1997.

[3] L. Song, Z. Sun, L. Duan, J. Gui, and G. S. McDougall, "Adsorption and diffusion properties of hydrocarbons in zeolites," Microporous and Mesoporous Materials, vol. 104, no. 1-3, pp. 115-128, 2007.

[4] M. J. Ahmed, A. H. A. K. Mohammed, and A. A. H. Kadhum, "Prediction of multi component equilibrium isotherms for light hydrocarbons adsorption on 5A zeolite," Fluid Phase Equilibria, vol. 313, pp. 165-170, 2012.

[5] M. J. Ahmed and S. K. Theydan, "Equilibrium isotherms studies for light hydrocarbons adsorption on $4 \mathrm{~A}$ molecular sieve zeolite," Journal of Petroleum Science and Engineering, vol. 108, pp. 316-320, 2013.

[6] N. Rosenbach Jr., A. Ghoufi, I. Déroche et al., "Adsorption of light hydrocarbons in the flexible MIL-53(Cr) and rigid MIL47(V) metal-organic frameworks: a combination of molecular simulations and microcalorimetry/gravimetry measurements," Physical Chemistry Chemical Physics, vol. 12, no. 24, pp. 64286437, 2010.

[7] M. Weilenmann, J.-Y. Favez, and R. Alvarez, "Cold-start emissions of modern passenger cars at different low ambient temperatures and their evolution over vehicle legislation categories," Atmospheric Environment, vol. 43, no. 15, pp. 2419-2429, 2009.

[8] B. Puertolas, M. V. Navarro, J. M. Lopez, A. M. Mastral, and T. Garcia, "Recent solutions for the abatement of hydrocarbon emissions during the cold start of light vehicles," Recent Patents on Chemical Engineering, vol. 4, no. 1, pp. 36-52, 2011.

[9] T. H. Yeon, H. S. Han, E. D. Park, and J. E. Yie, "Adsorption and desorption characteristics of hydrocarbons in multi-layered hydrocarbon traps," Microporous and Mesoporous Materials, vol. 119, no. 1-3, pp. 349-355, 2009.

[10] P. Eastwood, Critical Topics in Exhaust Gas Aftertreatment, Research Studies Press, Baldock, UK, 2000.

[11] E. L. First, C. E. Gounaris, J. Wei, and C. A. Floudas, "Computational characterization of zeolite porous networks: an automated approach," Physical Chemistry Chemical Physics, vol. 13, no. 38, pp. 17339-17358, 2011.

[12] D. W. Breck, Zeolite Molecular Sieves, Krieger Publishing Company, Malabar, India, 1974.

[13] R. M. Barrer, Zeolites and Clay Minerals as Sorbents and Molecular Sieves, Academic Press, London, UK, 1978.

[14] M. W. Ackley, S. U. Rege, and H. Saxena, "Application of natural zeolites in the purification and separation of gases," Microporous and Mesoporous Materials, vol. 61, no. 1-3, pp. 25-42, 2003.

[15] D. Caputo, F. Iucolano, F. Pepe, and C. Colella, "Modeling of water and ethanol adsorption data on a commercial zeoliterich tuff and prediction of the relevant binary isotherms," Microporous and Mesoporous Materials, vol. 105, no. 3, pp. 260267, 2007.
[16] H. Stach, U. Lohse, H. Thamm, and W. Schirmer, "Adsorption equilibria of hydrocarbons on highly dealuminated zeolites," Zeolites, vol. 6, no. 2, pp. 74-90, 1986.

[17] D. H. Lin, V. Ducarme, G. Coudurier, and J. C. Vedrine, "Adsorption and diffusion of different hydrocarbons in MFI zeolite of varying crystallite sizes," in Zeolites as Catalysts, Sorbents and Detergent Builders-Applications and Innovations, H. G. Karge and J. Weitkamp, Eds., vol. 46 of Studies in Surface Science and Catalysis, pp. 615-623, Elsevier Science Publishers B.V., Amsterdam, The Netherlands, 1989.

[18] A. V. Ivanov, G. W. Graham, and M. Shelef, "Adsorption of hydrocarbons by ZSM-5 zeolites with different $\mathrm{SiO}_{2} / \mathrm{Al}_{2} \mathrm{O}_{3}$ ratios: a combined FTIR and gravimetric study," Applied Catalysis B: Environmental, vol. 21, no. 4, pp. 243-258, 1999.

[19] F. Wang, W. Wang, S. Huang, J. Teng, and Z. Xie, "Experiment and modeling of pure and binary adsorption of $n$-butane and butene-1 on ZSM-5 zeolites with different Si/Al ratios," Chinese Journal of Chemical Engineering, vol. 15, pp. 376-386, 2007.

[20] S. Boulard, P. Gilot, R. Brosius, D. Habermacher, and J. A. Martens, "Perturbation and tracer chromatography study of hydrocarbon adsorption from simulated exhaust gas on Fe-MFI and MOR type zeolite catalysts," Topics in Catalysis, vol. 30-31, pp. 49-53, 2004.

[21] J.-H. Park, S. J. Park, I.-S. Nam, G. K. Yeo, J. K. Kil, and Y. K. Youn, "A fast and quantitative assay for developing zeolitetype hydrocarbon trap catalyst," Microporous and Mesoporous Materials, vol. 101, no. 1-2, pp. 264-270, 2007.

[22] J. M. López, M. V. Navarro, T. García et al., "Screening of different zeolites and silicoaluminophosphates for the retention of propene under cold start conditions," Microporous and Mesoporous Materials, vol. 130, no. 1-3, pp. 239-247, 2010.

[23] T. Kanazawa, "Development of hydrocarbon adsorbents, oxygen storage materials for three-way catalysts and $\mathrm{NO}_{x}$ storagereduction catalyst," Catalysis Today, vol. 96, no. 3, pp. 171-177, 2004.

[24] K. Higashiyama, T. Nagayama, M. Nagano et al., "A catalyzed hydrocarbon trap using metal-impregnated zeolite for SULEV systems," SAE Technical Paper 2003-01-0815, 2003.

[25] S. Kubo, M. Yamamoto, Y. Kizaki, S. Yamazaki, T. Tanaka, and K. Nakanishi, "Speciated hydrocarbon emissions of SI engine during cold start and warm-up," SAE Technical Paper 932706, 1993.

[26] A. Macario, A. Katovic, G. Giordano, F. Iucolano, and D. Caputo, "Synthesis of mesoporous materials for carbon dioxide sequestration," Microporous and Mesoporous Materials, vol. 81, no. 1-3, pp. 139-147, 2005.

[27] S. J. Gregg and K. S. W. Sing, Adsorption, Surface Area and Porosity, Academic Press, San Diego, Calif, USA, 1997.

[28] D. M. Ruthven, Principle of Adsorption and Adsorption Processes, John Wiley \& Sons, New York, NY, USA, 1984.

[29] F. Geoboldo, G. Spoto, S. Bordiga, C. Lamberti, and A. Zecchina, "Propene oligomerization on H-mordenite: hydrogenbondinginteraction, chain initiation, propagation and hydrogen transferstudied by temperature-programmed FTIR and UVVIS spectroscopies," Journal of the Chemical Society, Faraday Transactions, vol. 93, pp. 1243-1249, 1997.

[30] J. March, Advanced Organic Chemistry: Reactions, Mechanisms and Structure, John Wiley \& Sons, New York, NY, USA, 4th edition, 1992. 

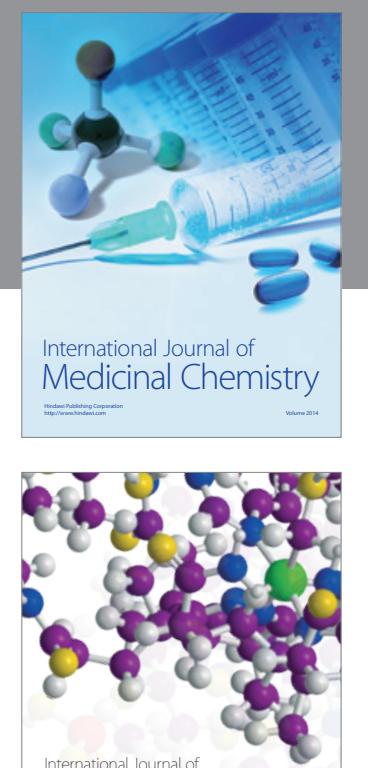

\section{Carbohydrate} Chemistry

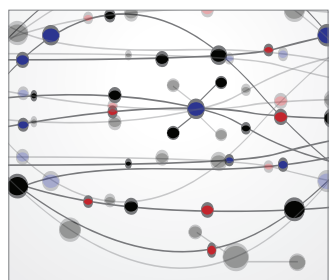

The Scientific World Journal
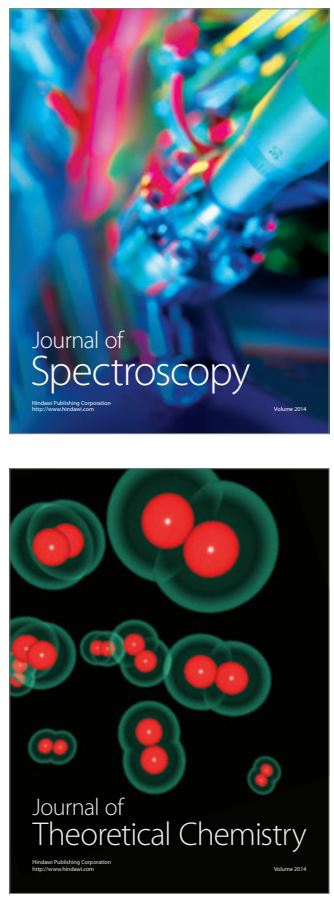
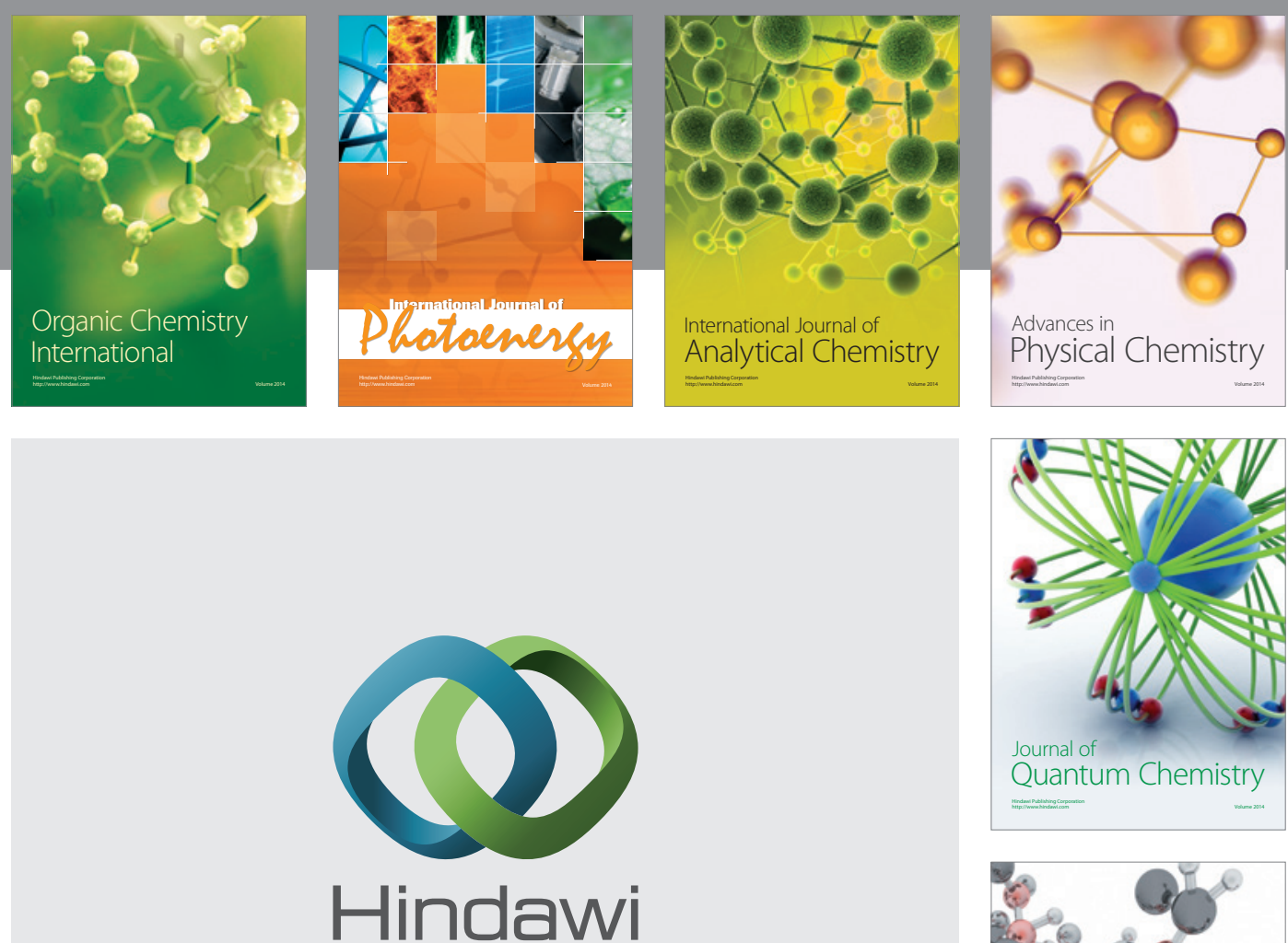

Submit your manuscripts at

http://www.hindawi.com

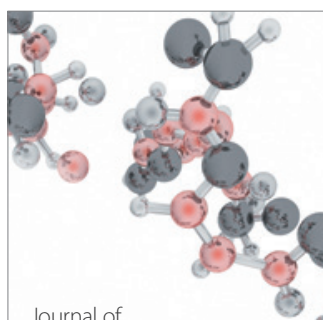

Analytical Methods

in Chemistry

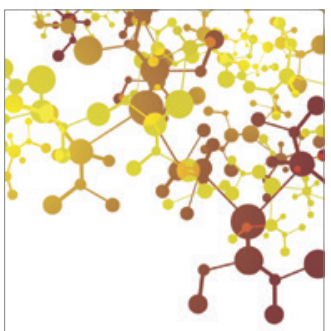

Journal of

Applied Chemistry

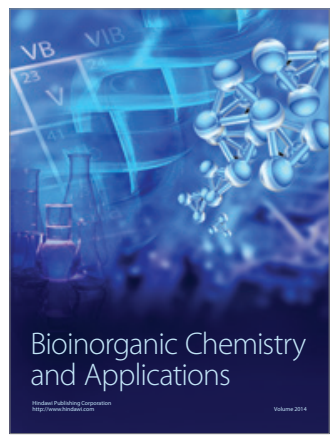

Inorganic Chemistry
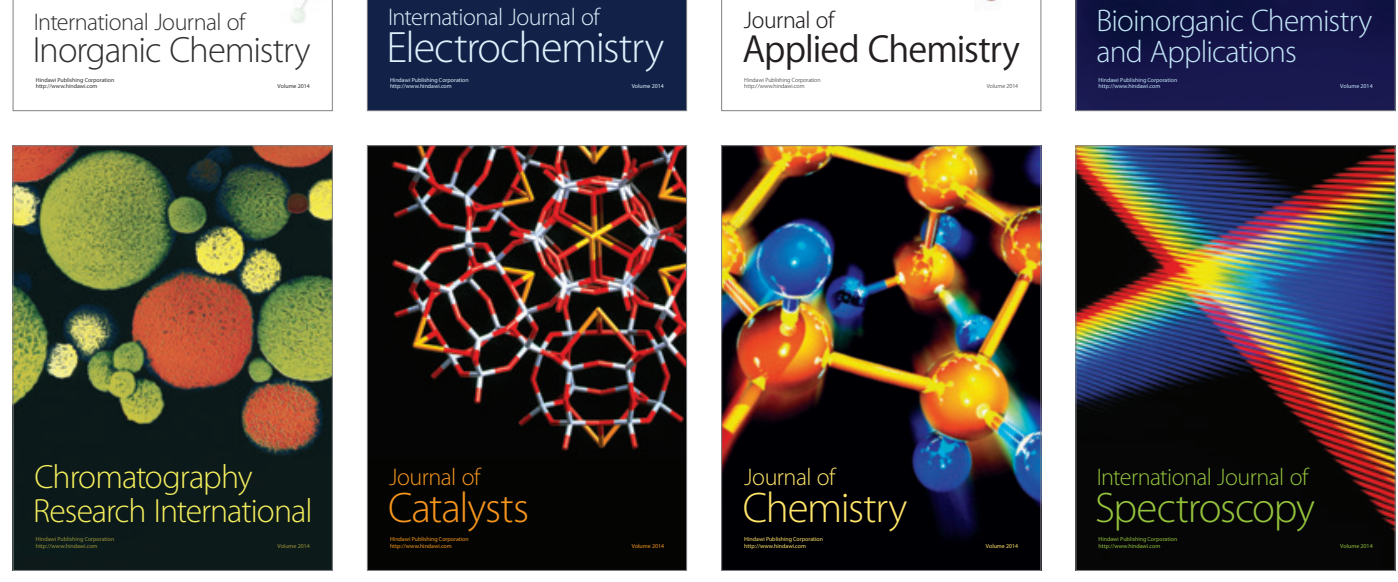